\title{
EDWARD SAID Y LA OTREDAD CULTURAL
}

\author{
Edward Said and Cultural otherness
}

\section{Claudia Zapata Silva*}

\section{RESUMEN}

Edward Said (1935-2003) es autor de una vasta obra que trata sobre cultura, literatura, música y política. Este trabajo aborda específicamente el concepto de cultura que orientó sus estudios y la posición crítica frente a planteamientos enaltecedores de la diferencia y la otredad concebidas como distancia radical entre Oriente y Occidente. El análisis está centrado en sus libros más identificados con el pensamiento postcolonial, donde vincula abiertamente la cultura con las relaciones desiguales de poder, entramado conflictivo en el que también involucra a las disciplinas del conocimiento occidental, de ahí la importancia que se asigna a su debate con la antropología.

Palabras clave: Cultura, otredad, diferencia, diversidad, humanismo.

\section{ABSTRACT}

Edward Said (1935-2003) has produced a vast work devoted to culture, literature, music and politics. This article approaches specifically the concept of culture that has guided Said in his studies as well as his critical opinion of views that extol difference and otherness, conceived as radical distance between West and East. This analysis is centered on his books most closely associated with postcolonial thought, where Said explicitly relates culture with unequal power relationships, a conflictive tangled web in which he exposes the involvement of the western disciplines, and therefore the importance assigned to his debate with anthropology.

Keywords: Culture, otherness, difference, diversity, humanism.

Recibido: 14.01.2008. Aprobado: 29.07.2008.

${ }^{*}$ Dra. (c) en Historia, mención Etnohistoria. Académica del Centro de Estudios Culturales Latinoamericanos Universidad de Chile.E-mail: clzapata@uchile.cl 
...la historia de la cultura no es otra que la historia de préstamos culturales. Las culturas no son impermeables; así como la ciencia occidental tomó cosas de los árabes, ellos las tomaron de los indios y los griegos. La cultura no es nunca cuestión de propiedad, de tomar y prestar con garantías y avales, sino más bien de apropiaciones, experiencias comunes, e interdependencias de toda clase entre diferentes culturas.

E. SAID, 1996 (1993):337.

\section{ENTRE DOS MUNDOS}

$\mathrm{E}$ N 1998, Edward W. Said publicó un hermoso artículo titulado "Entre dos mundos", donde adelantaba parte de las memorias que saldrían a la luz pública al año siguiente con el título de Fuera de lugar. Estas reflexiones biográficas se insertan plenamente en la temática de su obra, donde el lugar de enunciación de su autor ocupó un sitial preponderante pues se entendía a sí mismo resultado de los procesos culturales que analizó desde una perspectiva crítica, acercamiento que tenía como punto de partida la experiencia de un sujeto oriental en la nueva metrópoli mundial: los Estados Unidos. ¿Qué se siente venir de un país que ya no existe? ¿Cómo se enfrenta ser señalado como Otro, a veces de manera paternalista y en otras de manera violenta? Son temas que Said aborda en estas memorias, pero cuyos detalles más sorprendentes y anecdóticos son revelados en este artículo. Cito parte de estas confesiones: "A veces me daba cuenta de que me había convertido en una criatura peculiar para muchos, incluso algunos amigos, que suponían que ser palestino equivalía a ser algo mítico como el unicornio o una variante desahuciada del ser humano" (Said, 1998:109). Es decir, que incluso en el ámbito académico un colega palestino podía llegar a ser concebido como un sujeto exótico y observable, cosa que a nuestro autor le ocurrió en innumerables ocasiones: cuando una sicóloga quiso visitarlo en su casa sólo para saber cómo vivía (saliendo decepcionada porque encontró un piano), o cuando un publicista pidió con extraña insistencia comer con él antes de cerrar un acuerdo porque quería -según confesó su ayudante- ver cómo se comportaba en la mesa... Más allá de lo anecdótico (y cruel) de estos episodios, en años anteriores estas marcaciones de otredad habían sido más violentas en el contexto de un conflicto árabe-israelí en el cual Said ya había tomado partido (en 1985 su oficina de la universidad fue quemada por un grupo sionista).

Si bien estas situaciones estuvieron rodeadas de intenciones muy distintas, en todas ellas existe un núcleo común: el Otro oriental como dato anterior y determinante del sujeto en cuestión, una condición que se ubica por sobre la posición cultural compleja de nuestro autor (que él mismo utiliza con el objetivo de no homologar su experiencia de exilio y discriminación con la 
de quienes mayoritariamente protagonizan la diáspora palestina en calidad de refugiados): una educación refinada de cuño británico que recibió en El Cairo durante los años cuarenta por formar parte de una familia de élite en la colonia, cuyo proyecto había sido aproximarse lo más posible a la cultura de los colonizadores, de ahí su nombre que, como él mismo reconoce, emulaba al del Príncipe Eduardo de Inglaterra. En esta formación Said aprendió la estricta disciplina británica y alcanzó un conocimiento profundo del canon literario y musical de Occidente, sin embargo y como solía recordar, aquella aproximación a la cultura del colonizador tenía un límite estricto: "Aunque me enseñaron a creer y pensar como alumno inglés, también me enseñaron a comprender que era extranjero, un Otro no europeo, educado por mis superiores a entender mi condición y no aspirar a ser británico" (Said, 1998:98).

Fuera de lugar fue escrito en la ciudad de Nueva York, donde vivió gran parte de su vida, donde fue señalado (negativamente) como oriental y donde construyó su identidad palestina a partir de una biografía compleja: una madre originaria de Nazaret, un padre de Jerusalén (con nacionalidad norteamericana por haber participado en la I Guerra Mundial), educado en el Gezira Preparatory School y en el Victoria College de El Cairo y doctorado en literatura inglesa en los Estados Unidos. Aparte de narrar una infancia y adolescencia transcurridas en el Medio Oriente -“...un mundo perdido u olvidado en lo esencial" (Said, 2003a:11)- Fuera de lugar permite problematizar en la existencia de su propio autor la pertinencia del concepto de otredad para nombrar una cultura distinta de la occidental. Lejos de este supuesto, Said ha sostenido sistemáticamente en su obra -principalmente Orientalismo ([1978]2003b) y Cultura e imperialismo ([1993]1996a)- la ahistoricidad de este concepto, que tiene más que ver con Occidente (lugar desde el cual se enuncia) que con las culturas no occidentales.

Este trabajo tiene por objetivo destacar el aporte de Edward Said en la deconstrucción de las esencias culturales que continúan vigentes en la crítica contemporánea y cuyos riesgos permanecen por sobre la voluntad de valoración de los grupos que han sido inferiorizados culturalmente en distintos procesos de colonización desde el siglo XV.

\section{OTREDAD CULTURAL Y CRÍTICA CONTEMPORÁNEA}

La anécdota de la sicóloga que deseaba observar in situ la cotidianeidad de un oriental en los Estados Unidos pero que se retira decepcionada al descubrir que su morador cultiva la música occidental, entraña una actitud que ha ido ganando adeptos en las últimas décadas: el deseo de sujetos culturalmente puros de acuerdo con parámetros de autenticidad atemporales y externos

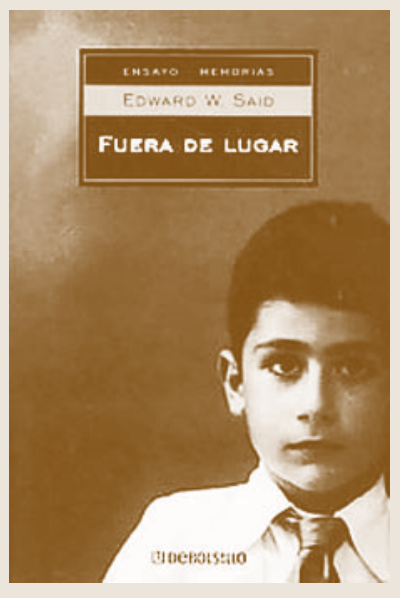




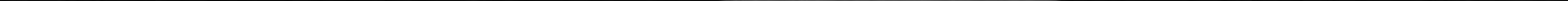


que deberían encarnar con fidelidad. La fascinación actual con la otredad cultural nos sitúa en un presente marcado en el ámbito académico y social por la crítica a la modernidad clásica y a las características particulares que hoy presenta esa crítica (considerando que esta actitud no es nueva en la historia del proyecto moderno). Me refiero a la correspondencia que se ha establecido entre modernidad, ilustración y Occidente, incluyendo al Estado nacional como su producto derivado. Frente a este conjunto pretendidamente homogéneo suele oponerse esta otredad que representa la existencia de un afuera para quienes no advierten futuro en el proyecto moderno, un afuera en el que se depositan esperanzas políticas y la posibilidad de una crítica radical a todo aquello que se busca reemplazar.

Si bien esta fascinación por lo culturalmente opuesto es un tema antiguo que ha recorrido distintos campos del conocimiento y de la creación artística (Hobbes y Gaugin son algunos ejemplos entre muchos), en la actualidad esta posición ha tomado fuerza a tal punto que se ha constituido en referente para una parte importante de la crítica contemporánea enfrentada a un público predispuesto a aceptar el principio de la dicotomía Oriente-Occidente o la existencia de un mundo no occidental difuso, pero mejor. Dicotomía en la que Occidente y la modernidad aparecen con una connotación negativa, haciendo que de manera automática se revista de características positivas a todo aquello que -se cree- se ubica afuera, erigiéndose como "lo otro".

Este auge se produce en un contexto histórico que facilita una mirada comprensiva: el fin de la guerra fría, la crisis de la izquierda y el protagonismo de sujetos que han dado vida a potentes movimientos sociales fundados en identidades culturales, genérico-sexuales, entre otras. Estos hechos, resumidos esquemáticamente, constituyen el marco en el cual re-emerge esta fascinación que puedo ejemplificar con el tema indígena en América Latina por ser el que me resulta más conocido. Tanto la crisis antes mencionada como el rol determinante que han tenido los llamados nuevos movimientos sociales han erigido a los movimientos indígenas como referente cultural y político para varios autores y cientistas sociales que han reformulado sus ideales libertarios, desplazando la crítica desde la burguesía y el capitalismo hacia la modernidad y la cultura occidental. De este modo, las sociedades indígenas son destacadas por su externalidad con respecto a ese Occidente moderno que se busca combatir en el ámbito cultural, teórico y epistemológico, posición que aparece como un atributo deseable per se. Es más, se cuentan autores que no han ocultado su deseo de reemplazar toda su formación académica occidental por la llamada epistemología indígena (lo que se le ha escuchado durante el último tiempo a Walter Mignolo), proyecto que parte de la base de una distancia insalvable entre indígenas y no indígenas. Varios son los autores latinoamericanos que sustentan sus trabajos en esta dicotomía, todos los cuales parecen coincidir -con matices por cierto- en que los indígenas constituyen una alternativa a la política tradicional, al 
conocimiento científico, al capitalismo y a la episteme moderna. Se podría citar al Enrique Dussel de El encubrimiento del indio: 1492 ([1992]1994), a John Beverley con Subalternidad y representación ([1999]2004), Silvia Rivera Cusicanqui con "La raíz: colonizadores y colonizados" (1993), y más recientemente a Javier Sanjinés con El espejismo del mestizaje (2005) ${ }^{1}$.

Mi inquietud por este tema surge de la revisión crítica de estos trabajos en el marco de una investigación que trata sobre los intelectuales indígenas, sujetos que escapan a estos compartimentos que separan de manera tajante lo indígena de lo occidental, pero que además pertenecen a sociedades indígenas que en el presente no se subordinan a la dicotomía señalada, y que probablemente nunca formaron ese polo en el cual se los confina pues los indígenas son señalados como tales con la colonización, de manera que el vínculo con Occidente -problemático, conflictivo, pero real- es un elemento ineludible sin el cual resulta imposible entender su trayectoria política, su desarrollo cultural y las respuestas que han ofrecido a la inferiorización cultural de la que han sido objeto desde que fueron nombrados como indios.

\section{CULTURA E HISTORIA}

La posición frente a la cual me he manifestado de manera crítica no deja de ser rescatable en una historia de exclusión legada por los procesos de colonización, pero al mismo tiempo es válido preguntarse por la real distancia entre estas concepciones positivas de una parte y negadoras de la otra. Más allá del juicio de valor, se comparte una base teórica que consiste en la dicotomía Oriente-Occidente donde las culturas aparecen como entes perfectamente delimitados e incompatibles. Para Said, en cambio, el problema no es el contacto sino la forma en que éste se produce, de hecho, afirmó que la comunicación y los préstamos en uno y otro sentido es inherente a las culturas, a tal punto que sería un ejercicio estéril discutir sobre la propiedad de tal o cual objeto (de ahí su discrepancia con la afirmación de lo propio en un sentido excluyente) $)^{2}$. Por lo tanto, el conflicto no radica en el cambio cultural sino en el tipo de relaciones que lo producen, es aquí cuando repara en la violencia del imperialismo moderno en todos los ámbitos: cultural, ideológico, económico, social y político.

Su concepto de cultura se alejó de otros que la ubican por sobre las rela-

\footnotetext{
${ }^{1}$ Trato este asunto con detalle en un artículo que se titula "Cultura, diferencia, otredad y diversidad. Apuntes para discutir la cuestión indígena contemporánea”, en prensa.

${ }^{2}$ Lo interesante de este argumento (contenido en la cita que da comienzo a este artículo a modo de epígrafe), es que Said advierte estas características en todas las culturas y en todas las épocas, no como un elemento propio del siglo XX favorecido por los medios de comunicación masivos, como parece apuntar el antropólogo James Clifford cuando analiza acertadamente la crisis de la autoridad etnográfica (Clifford, 2001: 29).
} 
ciones humanas, no contaminada ni intervenida por éstas (la superestructura en un lenguaje marxista clásico). Ya en Orientalismo, su famoso estudio de 1978, vincula el desarrollo de la cultura con los avatares de la historia, señalando que todo lo que se ha dicho sobre los orientales no puede pasar por alto el hecho colonial, es más, que ese acervo de conocimiento forma parte del engranaje colonial. Pero es en Cultura e imperialismo, publicado quince años más tarde, donde articula mejor una idea de cultura integrada a las relaciones sociales cotidianas, interferida por la historia, por los intereses de distintos actores y sus ideologías:

... la cultura es una especie de teatro en el cual se enfrentan distintas causas políticas e ideológicas. Lejos de constituir un plácido rincón de convivencia armónica, la cultura puede ser un auténtico campo de batalla en el que las causas se expongan a la luz del día y entren en liza unas con otras (Said, 1996a:14).

Said criticó Occidente, pero sin negar el vínculo con éste y sin aspirar al fin de ese contacto, actitud que lo aparta de la dicotomía señalada en el apartado anterior y lo reúne, de cierta manera, con aquellos pensadores anticolonialistas que supieron distinguir entre Europa y el eurocentrismo, entre Occidente y el colonialismo. Me refiero a intelectuales y activistas políticos que en su momento fueron los artífices de las primeras respuestas intelectuales al colonialismo en un ámbito sensible para su funcionamiento: el de la representación y la ideología. Son los casos de Aimé Cesaire y Frantz Fanon, cuya defensa encendida de las sociedades colonizadas de las cuales formaron parte no pasó por alto el beneficio del contacto entre las culturas ${ }^{3}$. No debe extrañar entonces que Cultura e imperialismo, libro en el que se hace cargo "del otro lado" con el tema de la resistencia, se sustente en el diálogo con estos autores, principalmente Fanon, en perjuicio de un Michel Foucault que lo acompañó en Orientalismo, pero que más tarde se volvió un obstáculo al calor de su compromiso con el pueblo palestino. Sobre las posibilidades políticas que abren uno y otro, hace un contraste lapidario:

\footnotetext{
${ }^{3}$ Aimé Césaire, en su Discurso sobre el colonialismo (1950), uno de las más potentes acusaciones contra el colonialismo europeo, señala: “...admito entonces que poner en contacto las diferentes civilizaciones es bueno; que es excelente casar mundos distintos; que una civilización, cualquiera que sea su íntimo genio, al replegarse en sí misma, se marchita" (Césaire, 1993:308). Por su parte Frantz Fanon, en Los condenados de la tierra (1961), también introduce distinciones entre Europa y el colonialismo, otorgando un sitial a la cultura occidental pero condenando el dominio establecido en su nombre: "Se trata, para el Tercer Mundo, de reiniciar una historia del hombre que tome en cuenta al mismo tiempo las tesis, algunas veces prodigiosas, sostenidas por Europa, pero también los crímenes de Europa..." (Fanon, 1963:291).
} 
Los dos autores se nutren de la herencia de Hegel, Marx, Freud, Nietzsche, Canguihelm y Sartre, pero sólo Fanon da a este formidable arsenal un sentido antiautoritario. Foucault, debido quizá a su desencanto respecto a las insurrecciones de los años 60 y con la revolución iraní, se desvía por completo de la política (Said, 1996a: 429-430).

Siguiendo esta línea, Said centró su obra en el estudio del imperialismo moderno, pero sin suponer que esa maquinaria que ha dejado tantas víctimas era inevitable en la historia europea. Tampoco renegó de la cultura occidental, aspecto que no consideraron algunos de sus detractores que lo criticaron por formular su análisis antiimperialista con los documentos y procedimientos de Occidente. Pero más allá de los ataques personales (que incluyeron intentos por desconocer su nacimiento en Jerusalén y su condición de oriental), este tipo de críticas colocan en evidencia concepciones opuestas de la cultura y de la resistencia, lo que se expresa en una tensión básica: ¿sólo quiénes inventan una idea pueden usarla? Fue la pregunta que rondó las luchas de liberación nacional en el Tercer Mundo y que también está presente en los movimientos de grupos subordinados hasta hoy. La idea de incompatibilidad cultural juega para uno y otro lado: para los que creen que las culturas inferiores sólo imitan (el eurocentrismo más conservador) y para quienes piensan que los miembros de estas culturas sólo deben resistir desde su particularidad cultural ${ }^{4}$. El análisis de la resistencia que hace Said incorpora la premisa del contacto, lo que en un contexto de colonialismo (también se podría agregar el neocolonialismo) le otorga una forma específica pues no se puede olvidar que la imposición violenta de una cultura se hizo en detrimento de otra señalada como inferior, afectando prácticas distintivas como la lengua y la memoria.

Desde esta perspectiva, la resistencia no consiste en descubrir espontáneamente la cultura propia, sino en abrir espacios cerrados por la ideología colonial para entender el presente y desnaturalizar esa ideología, emprender un viaje hacia el pasado para encontrar fragmentos de lo que fue negado y arrebatado. Es aquí donde se produce un doble movimiento en torno a la

\footnotetext{
${ }^{4}$ Recuerdo una entrevista al subcomandante Marcos, uno de los líderes del Ejército Zapatista de Liberación Nacional en Chiapas, México, realizada al poco tiempo de la rebelión de 1994, donde se le preguntaba si no era impropio que indígenas mayas recurrieran a la estrategia militar y a la política occidental, frente a lo cual respondió argumentando sobre la inviabilidad de pelear contra un ejército regular con arcos y flechas. Por cierto, el movimiento zapatista se debate también entre las expectativas de otredad cultural de algunos sectores de la nueva izquierda, que advierten en ellos la posibilidad de una acción política no contaminada por la ideología, las estrategias y los partidos. Por otra parte, ha sufrido también la descalificación de quienes piensan que se trata de indígenas manipulados por la ultraizquierda urbana: ambas posiciones se sustentan, como aquí he querido expresar, en la dicotomía Oriente-Occidente que en el caso indígena no reconoce su vínculo con los procesos nacionales y sus trayectorias de militancia política.
} 
lengua: habitar aquella que se comparte con los colonizadores y recuperar las que han sido proscritas o confinadas a espacios sociales reducidos (Said, 1996a: 352). Al mismo tiempo advirtió los peligros de esta búsqueda, como aquella de entender la diferencia no sólo en el origen sino también en el destino de los grupos que la reivindican, un ensimismamiento que vuelve a poner obstáculos al diálogo libre entre las culturas. Poniendo como ejemplo la metáfora de Caliban, apropiada en América Latina para representar a las culturas subordinadas por la colonización, señala:

Los peligros del chauvinismo y la xenofobia (“África para los africanos”) son muy reales. Es mejor la opción en que Caliban ve su propia historia como aspecto parcial de la historia de todos los hombres y las mujeres sometidos del mundo, y comprende la verdad compleja de su propia situación social e histórica (Said, 1996a: 333) .

La presencia de Occidente en la constitución de los sujetos coloniales -tanto en aquellos que han internalizado la ideología colonial como en aquellos que han podido sacudirse de ella- se advierte en estas prácticas de resistencia: "En esto consiste la tragedia parcial de la resistencia: en que, hasta cierto punto, debe esforzarse por recobrar formas ya establecidas por la cultura del imperio o, al menos, infiltradas o influidas por él" (Said, 1996a:327). Uno de los ámbitos donde la resistencia muestra al mismo tiempo su efectividad política y esta posición cultural compleja, es el de la representación, donde la instalación de voces propias constituye una subversión de la ideología colonial que la había monopolizado, tal como lo analizó con profundidad en Orientalismo, donde los discursos políticos, intelectuales y artísticos sobre el Oriente no contemplaban la voz de sus habitantes, para siempre mudos en aquellos textos. Por el contrario, la producción intelectual y los liderazgos políticos emergidos de las sociedades colonizadas introducían polifonía en el campo de la representación, abriendo la posibilidad de contrastar estas voces. El cambio fundamental lo constituye la aparición de los hasta entonces Otros nativos en la posición de narradores y actores políticos, abandonando el silencio al que los había condenado el orientalismo.

Esta resistencia, en todas las dimensiones señaladas, produjo la crisis de la representación metropolitana sobre los Otros, demostrando que éstos sólo adquieren funcionalidad en relación con quien los nombra. El concepto de otredad se revela aquí en su naturaleza ideológica, como un ingrediente

\footnotetext{
${ }^{5}$ Para seguir la disputa en torno a la figura de Caliban y otros personajes que componen la pieza teatral de Shakespeare, ver "Caliban" del cubano Roberto Fernández Retamar, publicado en 1972, donde hace una genealogía de las interpretaciones en torno a la obra y su propia reivindicación de Caliban como el personaje representativo de los sectores excluidos de la sociedad latinoamericana.
}

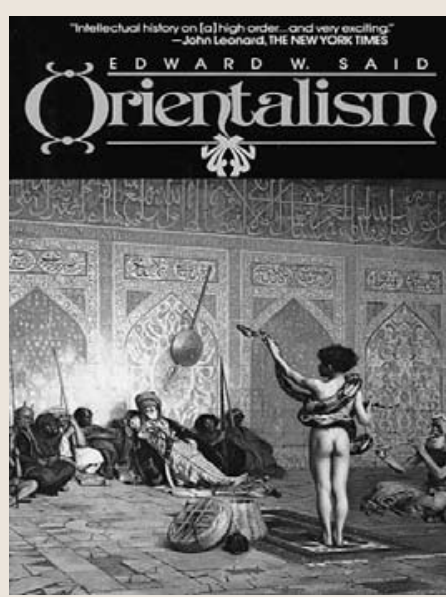


indispensable en la relación jerárquica que han fomentado los centros metropolitanos. El llamado de Said es a entender la otredad no en relación con las culturas no occidentales sino como un producto de Occidente mismo ${ }^{6}$ : “...ver a los Otros no como algo dado ontológicamente, sino como históricamente constituidos" (Said, 1996c:58).

Tal vez en este punto se ubica la principal contribución de Orientalismo, donde Said se aproxima a esa relación desigual desde sus huellas textuales. El libro se introduce en la historia de Occidente y su relación con el Oriente, referente histórico y geográfico que no es materia del estudio tal como se aclara en las primeras páginas, donde define el orientalismo como:

...un modo de relacionarse con Oriente basado en el lugar especial que éste ocupa en la experiencia de Europa occidental. Oriente no es sólo el vecino inmediato de Europa, es también la región en la que Europa ha creado sus colonias más grandes, ricas y antiguas, es la fuente de sus civilizaciones y sus lenguas, su contrincante cultural y una de sus imágenes más profundas y repetidas de lo Otro (Said, 2003b:19-20).

Si bien este libro no contiene una posición sobre cómo serían los orientales (categoría abarcadora que mira con distancia por no dar cuenta de la heterogeneidad cultural temporal y geográfica), sí deja clara la funcionalidad ideológica de la otredad cultural. Para Said, el Otro no es la otra cara de la moneda, ni los vencidos a quienes se desea reivindicar, sino la pieza fundamental de una relación dialéctica en la que ya habían reparado autores anticolonialistas como Césaire y Fanon ya citados. No puede pasar inadvertido entonces el hecho de que ese Otro existe en función del sujeto metropolitano, que se constituye como superior a partir de ese contraste.

Por cierto, Said no ha sido el primero ni el último en esta forma de entender las culturas, sólo basta recordar a Raymond Williams (de quien nuestro autor se declara tributario) reclamando la materialidad de la cultura e incorporando las variables del poder, la posición social y la historia en su discusión con el marxismo ortodoxo (Williams, 2000:129), o Terry Eagleton, cuya crítica al pensamiento posmoderno -ampliamente receptor y difusor de la fascinación por los otros- recuerda a los militantes de esta corriente el lugar secundario de los Otros en defensas de este tipo: "Si el 'otro' es reducido a ser cualquier cosa que desbarata mi identidad, ¿es esto un movimiento humildemente descentrador o una autocontemplación?" (Eagleton, 2004:135). En América Latina he descubierto hace un par de años el trabajo interesante en esta línea de la argentina Claudia Briones,

\footnotetext{
${ }^{6}$ A esto habría que agregar que todas las culturas son etnocéntricas y construyen sus otros, por lo tanto, no es una innovación de Occidente. El factor determinante es, entonces, el prestigio y la fuerza política de Occidente luego de los procesos coloniales.
} 
antropóloga de formación, quien habla del peso del esencialismo en su disciplina, hecho que explica la predilección por el estudio de los indígenas de comunidades rurales, entendidas como el espacio de la cultura originaria, el punto de referencia a partir del cual se distingue aquello original (esencial) de sus derivados (Briones, 1998:229). Esto ocurre a pesar del desarrollo dinámico de esta disciplina, que tras el fin de la Segunda Guerra Mundial y en medio del proceso de descolonización que se libraba en África y Asia, sintió la presión por actualizar sus marcos de comprensión teórica. Briones no anula la diferencia pero tampoco la entiende como un conjunto de rasgos consustanciales a ciertos sujetos y grupos, afirmación que tiene como corolario la desarticulación del binarismo que coloca en veredas distintas e irreconciliables a indígenas y no indígenas.

\section{LA ANTROPOLOGÍA}

Edward Said fue un autor polémico que participó activamente en el debate público hasta su muerte en septiembre de 2003, recibiendo críticas desde distintos frentes: por cierta literatura reacia al excesivo vínculo de esta disciplina con la historia; por los estudios orientales cuyos exponentes se vieron de pronto formando parte de una maquinaria ideológica que ha construido un Oriente irreal; por el sionismo y por el nacionalismo palestino en la arena de la real politik (sus enfrentamientos con Yaser Arafat fueron de público conocimiento) y por académicos que han celebrado la supremacía norteamericana tras la caída del muro de Berlín y la guerra de Estados Unidos contra el Medio Oriente, con quienes se enfrentó en los últimos años, especialmente tras los atentados que derribaron las torres gemelas de Nueva York en septiembre de 2001 (Francis Fukuyama y, sobre todo, Samuel Huntington). En este artículo y por la importancia del tema tratado, me referiré a su polémica con la antropología, disciplina que para este autor ocupa un lugar relevante en la construcción de los Otros.

Desde la mirada postcolonial que propone Said, la antropología forma parte de un contexto imperial y es funcional a su dominio de ultramar pues cumple con la misión de levantar un conocimiento especializado acerca de sus habitantes, sobre todo entre los años treinta y sesenta en que esta disciplina asume un lenguaje cientificista de acuerdo al paradigma de las ciencias sociales. La misma metodología sigue la geografía imperial cuando el antropólogo se traslada hacia las colonias africanas y asiáticas para observar de cerca a los colectivos no occidentales, cuya diferencia registra y traduce al público occidental, de lo cual surge un texto escrito que contiene la representación hecha por un sujeto metropolitano. Para Said, la práctica antropológica reproduce la relación de poder que subordina la colonia a la metrópoli, lo

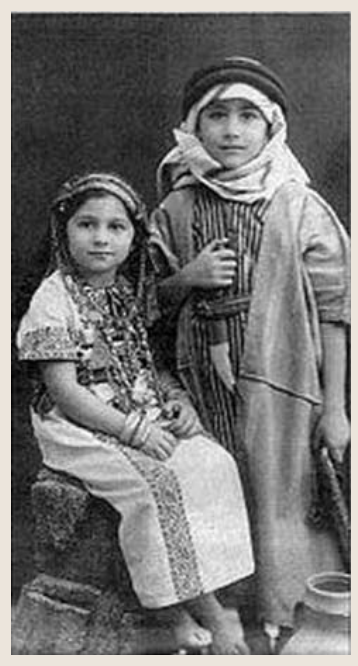

$65 \quad$ Atenea 498 
que se puede verificar en el lugar que ocupan esos Otros en la producción de ese conocimiento: el de informante nativo.

Si las últimas décadas del siglo XX fueron de crisis en las humanidades y las ciencias sociales (de límites disciplinarios, objetos y métodos), la crisis de la antropología se encuentra fatalmente unida al desmantelamiento del imperialismo europeo. La oleada de descolonización que se inició con la independencia de la India en 1947 modificó por completo el escenario sobre el cual se había desplegado la práctica antropológica, pues los movimientos de liberación nacional fueron acontecimientos masivos y heterogéneos que desmoronaron la imagen de una otredad radical, compacta e intraducible (excepto por quienes se erigían como sus especialistas). A la erosión de la otredad así entendida contribuye también el desarrollo vertiginoso de las comunicaciones que han acortado, en el espacio virtual al menos, las distancias geográficas.

En la perspectiva de Said, la antropología se constituye a partir de una premisa básica: la existencia de Otros radicales. ¿Qué ocurre entonces cuando el fundamento de una disciplina se diluye?, la respuesta de Said no ha dejado indiferentes a los antropólogos, incluso aquellos que han tratado de productivizar esta crisis para reformular su oficio en un sentido democrático. Dice Said:

... la antropología es, ante todo, una disciplina que ha sido constituida y construida históricamente, desde su mismo origen, a través de un encuentro etnográfico entre un observador europeo soberano y un nativo no-europeo que ocupaba, por así decir, un estatus menor y un lugar distanciado, es recién ahora a fines del siglo XX que algunos/as antropólogos/as buscan, frente al desconcierto que sienten por el estatus mismo de su disciplina, un nuevo "otro" (Said, 1996c:34-35).

Estas palabras formaron parte de un encuentro académico donde Said coincidió con varios antropólogos. Su conferencia abordó esta crisis de la representación antropológica e insistió en la asociación antropología-imperialismo incluso tras varios años de la crisis (asumida en lo general) de la antropología clásica: "Se dirá que he relacionado la antropología con el imperialismo demasiado crudamente, de una manera muy indiscriminada; a lo que respondo preguntando cómo -y realmente quiero decir cómo- y cuándo fueron separados" (Said, 1996c:38) ${ }^{7}$.

La crisis de las humanidades y las ciencias sociales se expresa en la inestabilidad de las bases sobre las cuales se constituyeron las disciplinas occidentales. La dimensión más productiva de esta crisis ha sido el surgimiento

\footnotetext{
${ }^{7}$ El título de esta conferencia expone de partida las tensiones que determinan el vínculo entre la antropología y su objeto de estudio: "Representar al colonizado. Los interlocutores de la antropología". El texto fue publicado por primera vez en 1989.
} 
de tendencias críticas que han sometido a revisión estos fundamentos con el fin de reformular el vínculo de sus disciplinas con un entorno que se ha transformado profundamente. La antropología no ha estado ajena a estas revisiones, algo que el mismo Said reconoce cuando menciona a la antropología marxista y la antropología antiimperialista, a la que se debe sumar la llamada antropología posmoderna, movimiento que surge en la academia norteamericana a principios de los años ochenta (Reynoso, 2003) y que se caracteriza por reconocer la mediación de relaciones de poder donde el antropólogo ocupa una posición privilegiada, prestando atención a los procedimientos escriturales en que esta relación se manifiesta (Clifford, 2001).

Uno de los exponentes más connotados de esta antropología es el estadounidense James Clifford. Por eso resulta interesante considerar la crítica que hace este autor a la propuesta de Edward Said en Orientalismo, pues se trata de una obra cuyo tema es la representación de la otredad desde una posición de poder y porque Clifford participa de una antropología que ha reconocido la responsabilidad de esta disciplina en la representación exotizada de los Otros.

En su famosa reseña de Orientalismo, publicada en 1980 y que en líneas generales es favorable a la obra, Clifford expone con lucidez las principales tensiones que recorren ese libro de Said, las cuales acompañaron al crítico palestino en los años siguientes y que fueron evolucionando conjuntamente con su compromiso político ${ }^{8}$. Una primera crítica (frecuentemente reproducida) señala que Said cuestiona el orientalismo pero sin proponer alternativa alguna. Clifford sostiene que no es posible hacer una crítica de esas dimensiones y al mismo tiempo eludir este desafío con el argumento de que escapa a los límites del estudio (Clifford, 2001:310). Otro reparo dice relación con que Said habría incurrido en los esencialismos que critica desde el momento que realiza distinciones gruesas como aquella que califica de orientalista a todos quienes suscriben la dicotomía Oriente-Occidente (lo que sería aparentemente contradictorio con la posición de oriental que este autor asume), homogeneizando tanto al orientalismo como al orientalista (Clifford, 2001:308 y 310). También existen objeciones con la delimitación del estudio: que ese Oriente deformado por el orientalismo (que según Clifford tampoco se define con exactitud) está ausente, cuestión que es real y que Said aclara en sus primeras páginas ${ }^{9}$.

${ }^{8}$ En la Introducción a Dilemas de la cultura, su influyente libro de 1988, Clifford apunta que la obra posterior de Said atenúa o disipa muchas de las dudas y críticas que despertó Orientalismo en 1978 (la reseña de Clifford se publicó en la revista History and Teory, № 19, en 1980).

${ }^{9}$ Otra delimitación importante fue la opción de analizar el imperialismo de Gran Bretaña, Francia y Estados Unidos, cuestión que también es objeto de duras críticas, incluyendo a Clifford y la reseña ya mencionada. Esta objeción fue la menos considerada por Said, quien en el Prólogo a la edición española del 2003 señala: “...ello no impidió que algunos críticos resaltaran el hecho irrelevante de que yo había desatendido el orientalismo alemán, holandés o italiano" (Said, 2003b:9). 
La mayoría de estas críticas apuntan a todo lo que se encuentra ausente en el libro, especialmente una alternativa a esa forma de establecer relaciones entre las culturas, cuestión que a la luz del desarrollo posterior de la obra y actividad política de su autor se antoja excesiva en la medida que la introducción de Orientalismo señala el objetivo de exponer un problema histórico-político en un escenario temporal y geográfico determinado, con una aproximación interdisciplinaria. La polémica parece tener origen en la naturaleza ideológica del tema y de su vigencia, más que en las inexactitudes y cabos sueltos que efectivamente se encuentran en Orientalismo.

Pero Clifford aborda otras cuestiones que sí me parecen neurálgicas en la obra de Said y que él vislumbró con lucidez en aquel libro que se considera fundador de la crítica postcolonial, la mayoría de las cuales se desprenden de la tensión entre Said y Foucault. Es interesante este reparo porque Orientalismo suele indicarse como un libro de cuño foucaultiano por estructurarse en torno a la noción de discurso y de formación discursiva ${ }^{10}$, pero se suele pasar por alto las tensiones y desplazamientos con respecto a este enfoque, lo cual ratifica que las distancias son anteriores al abandono definitivo de Foucault como soporte principal de sus reflexiones. Una primera tensión -correctamente identificada por Clifford- es la que se advierte entre el concepto de formación discursiva y la importancia que Said otorga a los autores, pues como sabemos, en Foucault la formación discursiva opera independientemente de éstos, a quienes determina, condiciona y predispone, sin embargo, Said se apoya en autores para introducir las variantes que pueden existir al interior del orientalismo (Clifford, 1998:311). Más que un uso totalmente libre de la teoría foucaultiana, en Orientalismo se aprecia un vínculo conflictivo que determina algunas ambivalencias claves, como aquella que identifica su crítico antropólogo entre la afirmación, por una parte, de un Oriente real que ha sido deformado, y por la otra, la imposibilidad de éste en aquellos pasajes donde Said pretende un alineamiento más fiel a los postulados foucaultianos (Clifford, 1998:308).

Otro nudo conflictivo, tal vez el más importante pues articula los anteriores, es la contradicción básica entre la reivindicación que hace Said del humanismo y el uso de estas teorías antihumanistas: "Las perspectivas humanistas de Said no armonizan con su empleo de un método derivado de Foucault, quien es por supuesto un crítico radical del humanismo" (Clifford, 1998:313). En su obra posterior, Said afianzará su adhesión al humanismo en detrimento de un postestructuralismo que lo cuestiona como parte de su crítica a la modernidad, pues vio en ese humanismo -necesariamente reformulado- la posibilidad de establecer un diálogo no jerárquico ni excluyente

\footnotetext{
${ }^{10}$ Said fue uno de los primeros autores de la academia estadounidense en utilizar el postestructuralismo francés. En Orientalismo se remite a dos libros de Foucault: La arqueología del saber y Vigilar castigar.
} 
entre las culturas. Este proyecto fue lo que determinó el distanciamiento con el que había sido su principal referente en 1978, sin que por ello renuncie a hacer un uso productivo y particular de estas propuestas, como aquella de la relación entre poder y saber, que él logra expandir para dar cuenta de la relación entre las metrópolis y sus colonias en uno y en otro sentido (cuestión por completo ausente en Foucault), pero apartándose de ese concepto de poder circulante que se ubica por sobre los sujetos, como ya aparece en Orientalismo, donde el uso de una categoría por entonces desprestigiada como la de imperialismo ya marca una distancia suficiente en la medida que involucra la existencia de centros de poder y sujetos que lo ejercen.

Más que el postestructuralismo de Foucault, lo que incomodó a Clifford fue esa defensa del humanismo que desde su perspectiva era contradictoria con la formulación de una crítica antiimperialista, de hecho, acusa la ambigüedad de Said por incurrir en los “... hábitos totalizantes del humanismo occidental" (Clifford, 2001:321), cuestión que el autor palestino refutó con firmeza en su último libro -Humanismo y crítica democrática- dedicado, precisamente, a defender la vigencia y necesidad actual del humanismo, recordando en su primer capítulo este reparo de Clifford (Said, 2006:28-29).

Este debate forma parte de la relación controvertida que estableció Said con la antropología, alcanzando también a las corrientes que la cuestionan desde su seno, pues aunque reconoce desplazamientos importantes respecto de la vertiente clásica, no ve en el trabajo de estos antropólogos una ruptura con esa tradición autoritaria: “... los recientes trabajos de investigadores marxistas, anti-imperialistas y meta-antropológicos (Geertz, Taussig, Wolf, Marshall Sahlins, Johannes Fabian y otros) nunca revelan un genuino malestar sobre el estatus sociopolítico de la antropología como un todo" (Said, 1996c:29) ${ }^{11}$.

\section{UN INTELECTUAL SITUADO}

La teoría postcolonial actual, inaugurada por Said en $1978^{12}$, tiene entre sus componentes principales un lugar de enunciación donde el autor especifica su procedencia (alguna de las ex colonias) y la complejidad cultural del sujeto

\footnotetext{
${ }^{11}$ En el caso específico de la llamada antropología posmoderna (término que acuña Stephen Tyler en 1983), aunque se avanza en la autoconciencia de los procesos escriturales y en los procedimientos mismos de la investigación, prácticamente no se tensiona el binomio antropólogo/informante, como tampoco la (auto)concepción del antropólogo como traductor de las diferencias culturales. Por ende, no se critica ni deconstruye la categoría de Otro (Ver la compilación de Reynoso, 2003).

${ }^{12}$ En otros trabajos hemos sostenido la necesidad de distinguir dos momentos en este tipo de reflexión intelectual: el primero que se extiende entre los años cuarenta y setenta al calor de los movimientos de liberación nacional en África, Asia y América Latina, donde destacan autores como
} 
que enuncia. Por cierto es una característica que recorre todas las obras de Said, incluso aquéllas donde no se manifiesta de manera explícita, como fue el caso de sus primeros estudios literarios que versaron sobre Joseph Conrad: "Durante años parecía estar yo pasando por el mismo tipo de vivencia en los trabajos que realicé, pero siempre a través de los escritos de otros", dice en relación a la obra del escritor polaco que escribía en inglés (Said, 1998:95).

En Said ese lugar de enunciación no podía ser otro que el de un oriental que habita la principal metrópoli del mundo contemporáneo, cuestión que no dejó indiferentes a sus críticos, quienes sospecharon de esta instalación frente a la refinada cultura occidental adquirida por Said desde su infancia en Egipto. James Clifford nos sirve nuevamente como ejemplo, pues su sospecha dice relación con la coherencia de ese lugar de enunciación con los argumentos de quien escribe y no al mezquino afán de deslegitimar el compromiso político de Said con los derechos del pueblo palestino. Para Clifford, no existe relación entre la "actitud oposicional postcolonial" -según sus propias palabras- y la experiencia de vida de quien la formula. Es el atrevimiento de instalarse fuera de la problemática que analiza lo que exaspera al antropólogo estadounidense:

El propio Said escribe de maneras que simultáneamente afirman y subvierten su propia autoridad. Mi análisis sugiere que no puede haber suavización final de las discrepancias de su discurso, puesto que es cada vez más difícil mantener una posición cultural y política "fuera" de Occidente, desde la cual se lo pueda atacar sin riesgo (Clifford, 1998:26).

Por cierto, Clifford está pensando en la maestría con que Said maneja la literatura, el arte y la historia de Occidente, cuestión que pone en serios aprietos la pretensión de ese afuera, salvo por una cuestión que no es menor: que Said no formula su identidad oriental y específicamente palestina a partir del principio de pureza cultural, requisito que como señaló en la mayoría de su producción intelectual posterior a Orientalismo, estaba lejos de integrar su horizonte de expectativas. Como se trató en el segundo apartado, el problema de Said no fue la existencia de Occidente, ni el diálogo con esta rica cultura, sino el tipo de relación imperial que en determinado período de la historia se estableció con otras tradiciones culturales, entendiendo que el contacto

Aimé Césaire, Frantz Fanon y Albert Memmi; y el segundo que tiene como telón de fondo la crisis de la bipolaridad que caracterizó a la guerra fría (a favor de Estados Unidos) y la globalización, una crítica influenciada por las corrientes postestructuralistas y postmodernas que surge de la academia norteamericana por parte de autores provenientes de las ex colonias, como es el caso de sus exponentes más connotados: Edward Said, Gayatri Spivak y Homi Bhabha. (Ver Rojo, Grínor; Salomone, Alicia y Zapata, Claudia, 2003). 
entre Oriente y Occidente tampoco era algo novedoso. En su caso, tampoco pudo ni quiso ocultar su particular configuración como sujeto de la élite nativa en una colonia, por lo tanto, su identidad oriental no dice relación con negar su componente occidental, sino con tomar partido y decidir nombrar aquello que había sido borrado por la historia imperial:

La división básica en el seno de mi vida es la que hay entre el árabe, mi idioma natal, y el inglés, el idioma de mi educación y mi expresión posterior como académico y profesor. Por esa razón, el hecho de intentar narrar una parte de mi vida en el idioma de la otra -por no hablar de las numerosas maneras en que los idiomas se mezclaban para mí y saltaban de un ámbito al otro- ha sido una tarea realmente compleja (Said, 2003a:14).

Este vínculo problemático, expresado en su propia existencia, es el que aborda largamente en Cultura e imperialismo, especialmente en el tema de la resistencia, estableciendo que ésta surge de los espacios de fricción entre colonizadores y colonizados, un análisis que completa el proyecto crítico iniciado con Orientalismo a la vez que ofrece la posibilidad de calibrar en su justa medida las formas de resistencia practicadas por su propio autor. La necesidad consciente de argumentar su condición de oriental es al mismo tiempo coherente con la defensa de un Oriente heterogéneo, no reductible a un puñado de rasgos exóticos ni posible de ser medido de acuerdo a parámetros de autenticidad que han impuesto las representaciones coloniales, a lo cual llamó precisamente orientalismo. La defensa de su identidad palestina forma parte de este empeño, pues Said se entiende a sí mismo como una forma más de ser palestino, sin estar ligado a lo que se supone deberían ser todos los integrantes de este pueblo (musulmanes principalmente).

El Clifford de 1980 también puso en duda la pertinencia de estos anclajes identitarios en el trabajo intelectual con el argumento de que éste debe responder a las condiciones de su entorno, en este caso del mundo globalizado, opinión que Said no suscribía en lo absoluto, a pesar de que la cuestión identitaria no lo convencía del todo (sus expresiones fundamentalistas al menos). Por este motivo dedicó tiempo y tinta al tema de los intelectuales en el mundo contemporáneo, defendiendo siempre el principio del intelectual situado que transparenta el lugar desde el cual habla, que reconoce intereses y el peso de su biografía, en oposición al conocimiento objetivo, técnico, experto o aséptico que adquirió impulso en los ochenta con el auge del modelo neoliberal. Esta idea de intelectual situado se opone al estereotipo del intelectual universal que se ubica por sobre las querellas de este mundo en el cual se refugian no pocos intelectuales, universalismo que para Said ha sido y es una falacia, no así la dimensión universal que es imprescindible para poner en diálogo las diferencias: "En otras palabras, hablar hoy de los 
intelectuales significa hablar específicamente de las variaciones nacionales, religiosas e incluso continentales del tema, porque cada una de dichas variaciones parece requerir una consideración independiente" (Said, 1996b:41). Esta concepción del trabajo intelectual también lo apartó de la figura del intelectual orgánico o militante, a la cual opone un intelectual crítico que aporta a una causa desde la exposición permanente de los conflictos que cruzan la lucha por ella. Desde esta vereda apoyó el movimiento palestino, al mismo tiempo que advertía sobre el peligro del integrismo y de las identidades excluyentes.

Su visión de la democracia y la diversidad tenía como punto de partida el concepto de cultura abierta ya comentado, de ahí su crítica a la categoría de otredad porque se opone, precisamente, a la diversidad que es necesario reconocer para articular espacios públicos democráticos. Frente a la espectacularización de las diferencias culturales -riesgo intrínseco a la otredad-Said y otros autores en esta perspectiva plantean un desafío que a mí me parece fundamental, aun cuando la búsqueda no esté concluida, el cual consiste en cómo pensar las diferencias culturales sin caer en riesgosos estereotipos que limitan la creatividad, el diálogo y el intercambio entre las culturas: “... preguntarse cómo se pueden estudiar otras culturas y pueblos desde una perspectiva libertaria, y no represiva o manipulativa" (Said, 2003b:49).

Para Said -y en esto sigue al Fanon de Los condenados de la tierra-, el diálogo cultural no jerárquico constituía la base necesaria para reconocer la humanidad de todos los habitantes del planeta. Su último libro, Humanismo y crítica democrática, concluido en mayo de 2003, a meses de su muerte y publicado al año siguiente, confirmó este compromiso con el humanismo y su convicción de que es posible y necesario habitarlo en una perspectiva emancipadora. En sus primeras páginas, que a la vez fueron las últimas de este autor palestino, señala:

Las culturas coexisten e interaccionan de un modo muy fructífero en una proporción mucho mayor de lo que combaten entre sí. Es a esta idea de cultura humanística como coexistencia y comunidad compartida a lo que pretenden contribuir estas páginas; $y$, con independencia de que lo consigan o no, me queda al menos la satisfacción de haberlo intentado (Said, 2006:18).

\section{REFERENCIAS}

Beverley, J. 2004 (1999). Subalternidad y representación, Madrid: Iberoamericana.

Bhabha, H. y Mitchell, W. J. T. (Comps.) 2006 (2004). Edward Said. Continuando la conversación. Buenos Aires: Paidós. 
Briones, C. 1998. La alteridad del “Cuarto Mundo”. Una deconstrucción antropológica. Buenos Aires: Ediciones Del Sol. Serie Antropológica.

Césaire, A. 1993 (1950). "Discurso sobre el colonialismo", en Fuentes de la cultura latinoamericana, Vol. II, Comp. Zea, Leopoldo, México D.F: Fondo de Cultura Económica, pp. 306-324.

Clifford, J. 2001 (1988). Dilemas de la cultura. Antropología, literatura y arte en la perspectiva posmoderna, Barcelona: Gedisa.

Dussel, E. 1994 (1992). El encubrimiento del indio: 1492 (Hacia el origen del mito de la modernidad), México D.F: Editorial Cambio XXI.

Eagleton, T. 2004 (1996). Las ilusiones del posmodernismo, Buenos Aires: Paidós.

Fanon, F. 1963 (1961). Los condenados de la tierra, México D.F: Fondo de Cultura Económica.

Fernández Retamar, R. 1998. Todo Caliban, Concepción, Chile: Ediciones Universidad de Concepción.

Memmi, A. 1972 (1957). The colonizer and the colonized, Boston: Beacon Press.

Reynoso, C. (Ed.) 2003. El surgimiento de la antropología posmoderna, Barcelona: Gedisa.

Rivera Cusicanqui, S. 1993. "La raíz: colonizadores y colonizados”, en Violencias encubiertas en Bolivia, Vol. 1, Coord. Albó, Xavier, Barrios, Raúl, La Paz: CIPCA-Aruwiyiri, pp. 25-139.

Rojo, G.; Salomone, A. y Zapata, C. 2003. Postcolonialidad y nación, Santiago: Lom.

Said, E. W. [1993] 1996a. Cultura e imperialismo, Barcelona: Anagrama.

. [1994] 1996b. Representaciones del intelectual, Barcelona: Paidós. 1996c. "Representar al colonizado. Los interlocutores de la antropología”, en Cultura y Tercer Mundo 1. Cambios en el saber académico, Comp. González Stephan, Beatriz, Caracas: Editorial Nueva Sociedad, pp. 23-59. . 1998. “Entre dos mundos”, en Fractal 9, pp. 93-112.

dori.

[1999] 2003a. Fuera de lugar, Barcelona: Random House Monda-

[1978] 2003b. Orientalismo, Barcelona: Random House Mondadori.

Said, E. W. [2004] 2006. Humanismo y crítica democrática. La representación pública de escritores e intelectuales, Barcelona: Random House Mondadori.

Sanjinés, J. 2005. El espejismo del mestizaje, La Paz: IFEA, Embajada de Francia, PIEB.

Williams, R. [1977] 2000. Marxismo y literatura, Barcelona: Ediciones Península.

Zapata, C. 2007. "Cultura, diferencia, otredad y diversidad. Apuntes para discutir la cuestión indígena contemporánea”, en Pensamiento latinoamericano: integración e interculturalidad, Edit. Santos, José, Santiago: IDEA-USACH, en prensa.

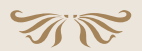

